\title{
The Role of Social Media in Developing an Effective Knowledge Management Process in Professional Service Firms
}

\author{
Syed Afzal Moshadi Shah \\ Assistant Professor, Department of Management Sciences, \\ COMSATS Institute of Information Technology, Abbottabad, Pakistan. \\ Email Address: afzalshah@ciit.net.pk \\ Dr. Iram Khan \\ Assistant Professor, Department of Management Sciences \\ COMSATS Institute of Information Technology, Islamabad, Pakistan. \\ Park Road, Islamabad 44000. \\ Email Address: iram.khan@fulbrightmail.org

\section{Dr. Shehla Amjad} \\ Professor / Head, Department of Management Sciences, \\ COMSATS Institute of Information Technology, Abbottabad, Pakistan. \\ Email Address: shehla@ciit.net.pk
}

Doi:10.5901/mjss.2013.v4n14p775

\section{Abstract}

Purpose: The study aims to develop a theoretical model to highlight the role of social media in developing effective knowledge management processes for professional service firms (PSFs). Design/ Methodology / Approach: The paper takes into account the latest fad of Social Media and extends the bounds of SECI model proposed by Nonaka and Takeuchi (1995). The newly dimension proposed in the SECI model capitalizes upon the distinctive features offered by social media. Social media such as Facebook, Twitter and Myspace as well as Internet forums, different types of blogs (weblogs, social logs, microblogging), wikis and podcasts etc have become household names nowadays. Introducing own social media by a company or managing an existing one should enhance its knowledge creating and sharing potential. A comprehensive review of theory, current literature and ongoing practices has been carried out in order to develop an understanding of the relevance of different variables, their expected impact on knowledge management process to develop our arguments. Findings: The current growing trend towards the use of social media and learning digital competencies among the employees offer a unique opportunity for knowledge intensive firms. Individuals with digital knowledge and access to internet facility actively engage in socializing over internet. PSF that develops its own online social media and/or facilitates other such activities that directly or indirectly affect the process of knowledge sharing will be able to amalgamate it wisely with its ongoing workplace knowledge management system.

Keywords: Knowledge Management, Social Media, Professional Service Firms

\section{Introduction}

In today's world, the most important asset in an organization is Knowledge and its custodians. It is due to the virtues of knowledge management that Wal-Mart has written a new history, where a retailer becomes more powerful than the supplier (reference). Empson (2001) has identified two main reasons for the growing popularity of knowledge management in recent years. First, in developed countries, due to the decline of capital and labor intensive firms, more attention is being given to industries that are more information intensive in nature. Secondly, advancement in information technology has resulted in developing procedures that are more systematic and explore areas of knowledge within organizations. We have selected PSF's for our study as they mainly employ highly educated employees and are knowledge intensive organizations (Lowendahl et al, 2001).

comScore (2011) reported an incredible figure of 1.36 Billion internet users worldwide during April 2011, with an increasing trend towards Social networking. In Europe, a total of $84 \%$ internet users use social networking and trend is 
high in both youngsters and old users. Redecker et al (2011) finds that social networking will provide an easy source of learning for junior and less experienced employees. They would easily interact with senior and more knowledgeable colleagues and would get benefit. Furthermore, social media will harness an environment of mutual cooperation and knowledge sharing, where knowledgeable workers will be given due recognition for their experience and knowledge.

This study proposes a new theoretical framework named 'SECI-SM ${ }^{1}$ Framework', while extending the work done by Nonaka and Takeuchi (1995) to a new dimension of KM that takes into account the recent popularity of Social Media as a means of communication and information sharing. SECI-SM model suggests that since knowledge management is largely a social activity that involves an ongoing interaction between individuals with explicit and tacit knowledge, 'Social Media' should be at the heart of SECI model. We believe that in the near future only those organizations would reap maximum benefits of knowledge management that will be able to root their knowledge management system in social media.

Call (2005) has rightly clarified the misconception of knowledge management as something that is technology dependent. Rather he believes that an excessive reliance on information technology would spoil the whole purpose of knowledge management. By highlighting the significance of social media, we are not suggesting an excessive use of technology to effectively undertake the process of knowledge management; rather we propose to adopt the golden rule of ice hockey 'Don't follow the ball, Go where the ball is going". Our point of argument is that social media is a reality now; people socialize and will keep on socializing over the internet. Dynamic and proactive organizations will capitalize upon this cost effective opportunity.

'Social media is a reality now; people socialize and will keep on socializing'

However, it should be kept in mind that despite several distinctive features associated with social media, it cannot be a substitute for conventional/prevailing knowledge management tools and techniques. It should be considered as another useful addition to the list.

'Social media is not a substitute for conventional knowledge management tools and techniques'

Give roadmap of future sections here.

Figure 1: SECl - SM Model

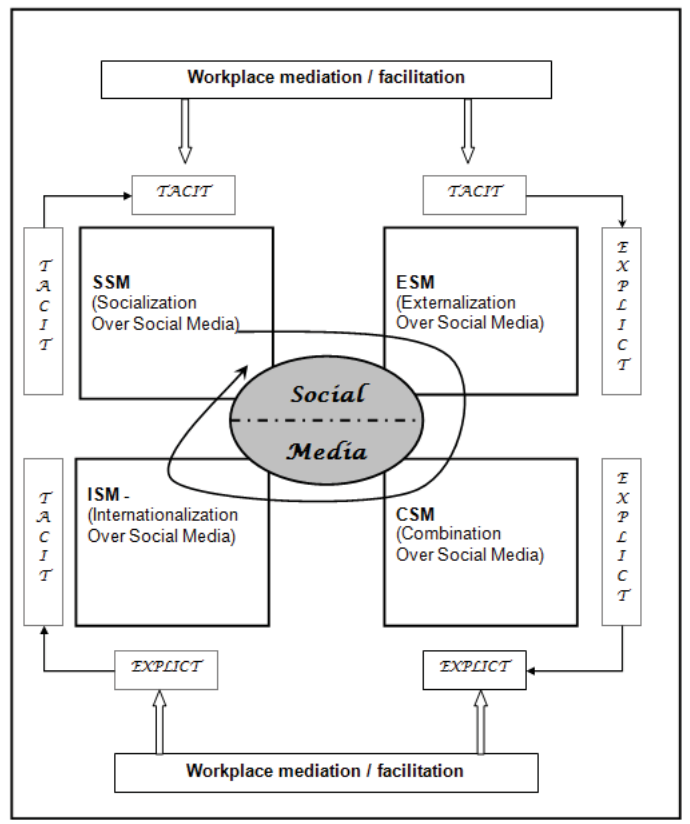

1 'SM' stands for Social Media. 


\section{Relationship between Social Media \& Knowledge Management}

ConnectingPeople(2010) defines Social Media as websites that help individuals to communicate and collaborate with each others with an added facility of content sharing. Huijster (2008) has mentioned websites that facilitate the process of social networking. According to him Facebook, Club Penguin, and Bebo are social networking websites. MSN Messenger, Myspace can also added to list that have not been given by Huijster (2008). The interaction of individuals can be in real time or delayed. Redecker et al., (2009) have thoroughly explained the entire process of interaction that takes place over the internet. They believe that these networking websites help individuals interact with their close ones by providing them the facility of email or instant messages. This internet facility, according to them, facilitate individuals to leave comments in real time called online forums, meet with different individuals, share their personal information through blogs, photos, videos and audios contents. Social media can, therefore, be defined as a process of socialization between individuals that occurs over the internet in static or dynamic time and within chosen privacy settings.

IBM and Lotus define knowledge management as a systematic process for innovation, responsiveness, competency and efficiency by effective use of contents and expertise (Pohs, 2001). ANSI defines Knowledge management as the process of producing, mediating, and using of knowledge and ways through which intellectual capital is managed (ANSI, 2001). Horwitch and Armacost (2002) view KM as a tool that helps organizations design effective policies, and amend actions in order to get desired results. According to them, it involves the process of generating, extracting, transforming and storing correct knowledge. Bhatt (2001) considers KM as a process of generating knowledge, checking its validity, knowledge presentation and distribution to get the desired applicability. [this para looks out of place; lack of coherence]

Bradley and McDonald (2011) have identified the following similarities and differences between social media and knowledge management:

Similarities:

- The use of technology for accessing information

- The need of individuals to generate information

- Sharing of information with others

Differences:

- Knowledge management is company driven (directed), whereas social media is self or peers driven

- Knowledge management is what company considers is important for you, whereas social media is what an individual or his/her peers considers is important for him/her.

Reichental (2011) argues that Social Media based on KM is superior to conventional KM. He believes that the former addresses behavioral and technical issues far better than conventional KM, as individuals feel more motivated towards knowledge sharing on social media and feel less threatened towards their knowledge or value loss. Especially, for technical guidance, individuals rely more on social media sources to seek knowledge than company websites.

\section{The Future of KM and role of Social Media}

Redecker et al (2011) foresee a huge impact of ICT on the entire process of learning. According to them, ICT will revolutionize the process of what is being learned, how is being learned, where is being learned and when is being learned. They view ICT features such as its dynamic nature, high level of flexibility, facilitating virtual environment, and customized learning facilities as key contributors to this change.

The Bruges Communiqué (2010) has envisaged that the process of learning would be life long in the near future. Hence, the learning and Knowledge Management should be done on enhanced flexible levels of delivery with highly customized trainings. It would further require an adequately defined system of evaluation for non-formal and informal learning. The report suggests that in future, the process of learning would become inevitable in that it will become a natural activity of every one and would sustain all their lives.

Bradley and McDonald (2011) argue that effective KM today demands mass level of collaboration. They believe that Social Media Technology provides matchless level of collaboration that cannot be furnished through conventional $\mathrm{KM}$. A self-driven and uncontrolled collaboration provides the right purpose of KM. Individuals can make small communities and interact freely.

Redecker et al (2011) foresee learning as a life long process. There will be high level of cooperation for knowledge sharing. Social media will diminish apparent barriers to learning such as age, seniority, gender etc. Employees will voluntarily and actively participate in such networks and communities in order to fulfill mutual benefits of knowledge 
sharing.

Redecker et al (2011) have identified the following benefits that organizations can get through enabling effective social networking processes:

a) Junior staff will easily get tacit knowledge

b) Senior staff will get the recognition of their knowledge base

c) Seniors will continually upgrade themselves with new developments in knowledge

d) A more cooperative culture of knowledge sharing would prevail

e) The unique feature of ICT would make it possible to enable knowledge creation, knowledge storing, knowledge sharing and knowledge up-gradation.

\section{Social Media- A household name}

According to comScore (2011), European countries spend almost a day every month (24:20 hours) on activities such as social networking, photo sharing and community activities. The study has further revealed that young European internet users between the ages of 15-34 years have decreased their email, instant messengers and portals and have shifted towards social networking sites. European internet users above the age of 35 years have also increased spending their times on social networking by $+38 \%$. However they still remained active users of emails. We believe similar results would be valid for the rest of the world as well.

A study conducted by Reston (2010) on gender wise social networking over internet revealed interesting facts. The study shows that out of the whole social networking takes place over the internet female contribution is $56.6 \%$. On average a female spent 5.5 hours during the month of May, 2010, where as a male participant spent 3.9 hours.

Another study by comScore (2011) on the most popular websites and their usage in Eurpoian countries during April 2011 revealed that Google Sites is the most popular with 329 million visitors, followed by Microsoft where visitors were 329 million and Facebook.com with 269 million [collect latest information]. If we segregate this information on the basis of facilities provided by each website, we can safely assume that Google is a search engine, Microsoft is mostly used for emails, whereas facebook.com is a social media. The study indicates the massive popularity of facebook.com being a social media on which a user spent 283.6 minutes [per day/week/month/year?]. Hence, facebook.com is assuming a central role in the lives of Europeans, as it is the highest time spent by individuals on average.

Figure 2: Top 5 websites visited in Europe during April 2011

\begin{tabular}{|l|c|c|c|}
\hline \multicolumn{1}{|c|}{ Properties } & Total Unique Visitors (000) & Total Pages Viewed (MM) & Average Minutes per Visitor \\
\hline Total Internet : Total Audience & 365,274 & 899,385 & $1,450.1$ \\
\hline Google Sites & 329,765 & 87,594 & 170.9 \\
\hline Microsoft Sites & 269,278 & 24,291 & 177.7 \\
\hline Facebook.com & 236,935 & 115,543 & 283.6 \\
\hline Wikimedia Foundation Sites & 149,211 & 2,046 & 11.8 \\
\hline Yahoo! Sites & 137,792 & 8,515 & 67.4 \\
\hline
\end{tabular}

Source: comScore (2011)

\section{SECI Model}

SECI Model is a theoretical model of the process of knowledge creation within organizations developed by Nonaka and Takeuchi (1995). The letter ' $S$ ' in the model stands for Socialization, 'E' for Externalization, 'C' for Combination and 'I' for Internalization. The model suggests knowledge management as a social activity that involves an ongoing interaction of individuals with explicit and tacit knowledge. The SECI model was claimed to be universal in nature by its authors. However, Weir and Hutchings (2005) have challenged the universality of SECI Model, though Andreeva and Ikhilchik (2011) believe that the SECI model cannot be supported or rejected on the basis of empirical findings. 


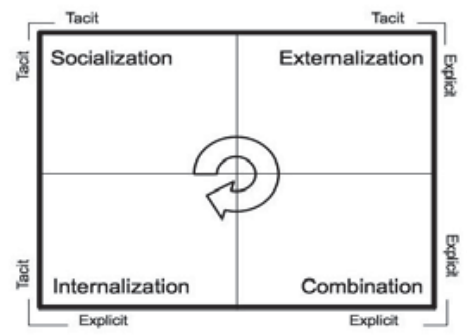

Source: Nonaka and Takeuchi (1995)

According to this model, the process of interaction between two types of tacit knowledge yields another type of knowledge through a process called Socialization. The process of converting tacit into explicit Knowledge is termed as Externalization. The process of mixing and merging different types of explicit knowledge and creating a new type of knowledge is called Combination, whereas the process of converting explicit knowledge into tacit knowledge is called Internalization. The spiral in the middle denotes the process of knowledge creation as an on-going process.

The model provides useful insights into the dynamic nature of knowledge and its generation. However the spiral movement can be anti-clockwise etc. Firestone and McElroy (2003) have criticized the model for not taking into account the implicit nature of tacit knowledge, referring to Polanyi (year) who believed that tacit knowledge can be experienced not shared.

\section{SECl-SM Framework}

Figure 1 should come round about here.

SECI-SM extends the SECI model proposed by Nonaka and Takeuchi (1995) to a new dimension of KM that takes place on the Internet. SECI-SM also overcomes some of the limitations associated with SECI model. Figure 1 represents the diagramed form of the model. It shows the spiral movement of the knowledge creation through Tacit to Explicit forms of knowledge interaction taking place over the Internet. SECI-SM contains the following four dimensions

\subsection{Socialization over Social Media - SSM}

It is defined as the interaction taking place between different individuals sharing tacit knowledge over social media yielding different types of knowledge that help organizations to increase the knowledge base and improve KM. theoretically correct, but how do they socialize on the net. There are means available which need to be added here.

\subsection{Externalization over Social Media - ESM}

The process of converting tacit knowledge into explicit Knowledge resulting from the interaction of individuals taking place over the social media is called Externalization over Social Media - ESM. Again the same question?

\subsection{Combination over Social Media - CSM}

The process of mixing and merging one type of explicit knowledge into another type of explicit knowledge and creating a new type of knowledge resulting from the interaction of individuals taking place over the social media is called Combination over Social Media or CSM. Same question.

\subsection{Internationalization over Social Media - ISM}

The process of converting the Explicit type of knowledge into tacit knowledge type resulting from the interaction of individuals taking place over the social media is called is called Internalization over Social Media - ISM.

All this is too simplistic and "how" part needs to be added here. This is very important.

The spiral in the middle denotes the process of knowledge creation as an on-going process. It is important to note that the model is not undermining the importance of prevailing or ongoing workplace Knowledge Management efforts 
being carried out by organizations.

\section{SECI-SM: A solution to KM problems}

We would discuss SECI-SM in the light of eight issues to knowledge management raised by Firestone and McElroy (2003), and would try to develop an argument in favor of SECI-SM model being superior.

\subsection{KM independent of strategy;}

Firestone and McElroy (2003) believe that true knowledge management should not be confined to strategies, as they consider knowledge to develop strategies has also come through the processing of knowledge. Hence the introduction of Social Media to SECI Model is an attempt to realize this aspect of knowledge management. Social Media with its slice-oflife touch provides a unique opportunity for evolving a strategy on ongoing basis.

\subsection{SECI Model and oversimplification of Tacit Knowledge}

Firestone and McElroy (2003) believe that SECl model is over simplified and does not take into account the true nature of implicit knowledge. According to them an implicit (tacit) knowledge can be felt and can't be transferred. We believe that by the introduction of social media, individuals will interact freely and without the fears of being monitored or observed, hence the chances for transfer of tacit knowledge would become easier as compare to conventional methods. We believe that Tacit knowledge becomes your second nature and it can be effectively transferred if the individual is relaxed and natural.

Talk about learning and sharing through youtube, khanacademy.org, ehow.com and forums, which allow people to meet over the net interactively and share tacit experiences, which were earlier only to be learnt through personal face to face contact.

\subsection{Introducing Knowledge Portal}

Firestone and McElroy (2003) make a distinction between Enterprise Information Portal (EIP) and Enterprise Knowledge Portal (EKP). They believe that what is normally hyped as EKP is actually EIP, a means to untested knowledge integration and dissemination. We believe that it is important to distinguish between information providing and Knowledge Portal. The former is more of a static website which is updated periodically, while the latter, in the words of Feng et al (2010), should cover knowledge resources, knowledge sharing, cross-platform retrieval system, virtual reference and user management systems. In this sense, it is similar to social networking. According to O'Dell \& Hubert (2011), social networking allows people to create their profiles in online places, filter friends and experts who can participate and share in activities with confidence and trust. Social networking here becomes an asset to initiate and sustain a relationship. It is basically user driven, participative and designed to allow people to opt in and out themselves and others, giving the members/users choice to select their peers and mentors.

\subsection{Making an open enterprise}

The discussion above points towards the openness, flexibility and democratic nature of Enterprise level Knowledge Management, which is an essential part of social media. It helps in forging new and reinforcing old relationships that gives a sense of belonging to employees in a large organization. The informality of relationship also contributes in the sharing and creation knowledge and best practices.

\subsection{Creating communities of inquiry}

Social media already addresses this issue raised by Firestone and McElroy (2003). However, the world has moved on since 2003, and now we have Communities of Practice. Social media not only helps in the creation of communities within the employees of that particular organization, rather it extends this community group beyond organizational boundaries. The beauty of such a social media is that the content shared with one member is accessible and searchable to all and remains available for years unless removed from the community pages. Furthermore, the content is retained even after 
the employee has left the organization. Content is not limited to written words only, rather its scope now extends to podcasts, capturing and retrieval of visible expressions and experiences which used to be available through face to face interaction. Now members can use each others as sounding boards validating their practices and as a result integrate local knowledge with a global experience. Some of the communities are truly global such as ConocoPhillips,Fluor and Schumberger (O'Dell \& Hubert, 2011). The introduction of Web 2.0 and Enterprise 2.0 has added a new dimension to knowledge sharing with distributed user-friendly applications (Bohringer et al 2009). This requires an ethical, human, legal due diligence from the organization. A small mistake can cause huge damage to the organization.

\subsection{Developing comprehensive KM metrics}

Firestone and McElroy (2003) advise a system metrics approach for effective KM. SECI-SM framework complements the different sub-components of knowledge lifecycle categories pointed out by the authors. The emergence of communities of practices covers the whole cycle of knowledge creation, acquisition, integration and evaluation etc. in the knowledge production set. Similarly, sharing, teaching, searching and broadcasting of knowledge is also integrated at the level of communities. The potential of both the individual and organizations are utilized for knowledge enhancement. The discussion transpires that the SECI-SM framework allows for the accommodation of comprehensive knowledge management metrics.

\subsection{The development of value theory in KM}

Knowledge Management based on social media or Knowledge Evaluation does not require a value theory or a prescriptive or normative approach to be used a touchstone for acceptance. Knowledge is treated as heterogeneous and permits non-conformism as a standard for creativity. As such, it provides flexibility and freedom to a junior employee contribute to the body of knowledge and be heard. Value is only given to an individual who makes valuable contribution to knowledge. We will call social media as a free economy of knowledge. We believe that a perceived valuable knowledge will be demanded higher than less perceived knowledge. Individuals that will possess the perceived valuable knowledge will be rated higher and will be appropriately acknowledged and recognized.

Social media is a free economy of knowledge. A perceived valuable knowledge will be demanded higher than less perceived knowledge.

\subsection{KM Standards}

SECI-SM framework visualizes knowledge management so dispersed and diffused that the only standard which can survive the test of time and space is one of flexibility and heterogeneity. Therefore, the foul play pointed out by Firestone and McElroy (2003) when standards of an organization are adopted and presented as the standards for the world of Knowledge Management will not be possible.

\section{Conclusion}

In short, social media has exposed KM to a whole new dimension. PSF's that would realize its importance and would develop their strategies around this will get benefits of first mover advantage. It would help them to gain competitive advantage and broaden their knowledge base. SECI-SM offers a unique combination of prevailing KM practices with added advantage of capitalizing upon Social Media. Reichental (2011) believes that by the introduction of social media, a new dynamic of community of knowledge has come into play, which poses a huge challenge to the management. It should be viewed as an opportunity rather than a threat. The world has moved to a level of "collective intelligence" where "intelligent enterprise[s]" adjusts well in its environment and behaves according to market circumstances (Delic \& Riley, 2009: 50).

SECI-SM addresses the concern shown by Weir and Hutchings (2005) on SECI Model's universal application [use their concerns in the text before Conclusion. Ideally, there should not be any reference in Conclusion]. Individuals using social media share certain characteristics that make them a homogeneous group but believe in the permanence of heterogeneity.

Social Media should be viewed as an opportunity rather than a threat. 


\section{References}

Andreeva, T. and Ikhilchik, I. (2011), Application of the SECI Model of Knowledge Creation in Russian Cultural Context: Theoretical Analysis, Knowledge and Process Management, Wiley Online Library Vol 18, No. 1 pp 56-66

ANSI (2001), "Knowledge management - vocabulary: candidate terms and definitions" [Online] available at: www.gkec.org/GKECdraftVocabulary_pdf; dated 01/12/2011.

Bhatt, G. (2001), "Knowledge management in organizations: examining the interaction between technologies, techniques, and people", Journal of Knowledge Management, Vol. 5 No. 1, pp. 68-75.

Bohringer, M., Gluchowski, P., Kurze, C., \& Schieder, C. (2009). On the role of social software techniques for the design of selforganising enterprise reporting portals (pp. 153-158).

Bradley, A.J. and McDonald, M.P (2011), Social Media versus Knowledge Management, HBR Blog Network, [Online] Harvard Business Review, Accessed on http://blogs.hbr.org/cs/2011/10/social_media_versus_knowledge.html dated: 12/11/2011

Bruges Communiqué (2010). Communiqué of the European Ministers for Vocational Education and Training, the European Social Partners and the European Commission, meeting in Bruges on 7 December 2010 to review the strategic approach and priorities of the Copenhagen process for 2011-2020. http://ec.europa.eu/education/lifelong-learning-policy/doc/vocational/bruges_en.pdf.

Call, D. (2005), Knowledge Management - Not Rocket Science, Journal of knowledge management, Emerald Group Publishing Limited, Vol. 9 No. 2, pp. 19-30

ComScore. (2011). 2010 Europe Digital Year in Review [Online] Accessed from http://www.comscore.com/Press_Events /Press_Releases/2011/6/comScore_Releases_European_Engagement_and_Top_Web_Properties_Rankings_for_April_2011 on 06/12/2011.

ConnectingPeople(2010), Digital Learning Platforms, Research Series Paper No. 2, Education Policy and Research Division, Research and Innovation Department of Education and Early Childhood Development Melbourne.

Delic, K. A., \& Riley, J. A. (2009). Enterprise Knowledge Clouds: Next Generation KM Systems? (pp. 49-53).

Empson, L. (2001). Introduction - Knowledge Management in Professional Service Firms, Human Relations, Sage Publications. Vol. 54 No. 7, pp. 811-817

Feng, L., \& others. (2010). Research on the Construction of the Knowledge Service-oriented Learning Knowledge Portal System in Universities. Information Studies: Theory \& Application, 1.

Firestone, J.M and McElroy, M.W (2003), The new knowledge management, special focus, the new knowledge management. http://www.kmci.org/media/New_Knowledge_Management.pdf

Horwitch, M. and Armacost, R. (2002), "Helping knowledge management be all it can be", Journal of Business Strategy, Vol. 23 No. 3 , pp. 26-32.

Huijster, H. 2008, 'Exploring the educational potential of social networking sites:the fine line between exploring opportunities and unwelcome imposition', Studies in Learning, Evaluation, Innovation and Development, vol. 5, no. 2, pp. 45-54.

Lowendahl et al, (2001), 'Knowledge And Value Creation In Professional Service Firms: A Framework For Analysis', Human Relations, Sage Publications. Vol. 54 No. 7, pp. 911-931.

O'Dell, C., \& Hubert, C. (2011). The New Edge in Knowledge: How Knowledge Management Is Changing the Way We Do Business. John Wiley \& Sons.

Pohs, W. (2001), 'Practical Knowledge Management: the Lotus Discovery System', 1st ed., IBM Press, Double Oak, TX, pp. 1-2.

Redecker, C. et al (2011), 'The Future of Learning: Preparing for Change', JRC Scientific and Technical Reports, Institute for prospective technological studies, European Commission.

Redecker, C., Alla-Mutka, K., Bacigalupo, M., Ferrari, A. \& Punie, Y. (2009), 'Learning 2.0 The Impact of Web 2.0 Innovations on Education and Training in Europe'. Final Report. JRC Scientific and Technical Report. Available at: $<$ http://ftp.jrc.es/EURdoc/JRC55629.pdf>.

Reichental, J. (2011), 'Knowledge management in the age of social media, The days of the single, authoritative voice are coming to an end'. The community has prevailed, [Online] Oreilly Radar, Accessed on http://radar.oreilly.com/2011/03/knowledgemanagement-social-media.html dated 05/11/2011

Reston, V. A (2010), 'Social Networking Sites Reach a Higher Percentage of Women than Men Worldwide', ComScore, [Online] Accessed from http://www.comscore.com/Press_Events/Press_Releases/2010/7/Social_Networking_Sites_Reach_a_Higher Percentage_of_Women_than_Men_Worldwide on 01/12/2011

Weir, D. and Hutchings, K (2005), 'Cultural embeddedness and contextual constraints: knowledge sharing in Chinese and Arab cultures', Knowledge \& Process Management, Wiley Online Library Vol 12 No 2 pp89-98 